\title{
Online Learning as Embodied, Socially Meaningful Experience
}

\author{
Tim Fawns $^{1} \cdot$ Gill Aitken $^{1} \cdot$ Derek Jones $^{1}$ \\ Published online: 31 May 2019 \\ (C) Springer Nature Switzerland AG 2019
}

If there is no soul in computer-music then it's because nobody put it there (Bjork 2019)

Two common views about online learning are that communication and relationships are inherently poorer online and that online learning can be scaled up without significant additional cost. Online learning has been identified as a key growth area for the higher education sector, often without a realistic consideration of resource requirements or an appreciation of the transformative value that online education can have for students.

In our context of taught postgraduate programmes, 'online' is a place where meaningful relationships, based on trust, can develop. Our students, through dialogue with an interdisciplinary and international online community, have developed critical and analytical ways of thinking that have extended their capacity to influence practice and policy in their local settings (Aitken et al. 2019). However, building an academic community takes time and becomes increasingly difficult amidst a global, market-led, neoliberal drive for universities to dramatically increase numbers of students (Jones 2019). This puts considerable pressure on teaching staff and poses risks for the quality of education. In this commentary, we take a critical postdigital perspective (Fawns 2019), in which all forms of education must account for a complex integration of digital, social and material elements, to reject reductionist approaches to growth in online learning.

We challenge the perception that the experiences of online learners are limited by distance or technology. Rather, we argue, the limiting factors are time, policy, infrastructure and pedagogy. The blunt depiction of online learning as a unified concept, with

Tim Fawns

tfawns@ed.ac.uk

Gill Aitken

Gill.Aitken@ed.ac.uk

Derek Jones

Derek.Jones@ed.ac.uk

1 University of Edinburgh, Edinburgh, UK 
inherent properties, can be seen in policies, advertisements, blog posts, social media comments and even in educational research. Take this statement from Bergstrand and Savage on why, according to them, online tutors treat students with less respect: '...by separating students from teachers in space, online classes prevent the face-to-face interactions critical to the student-teacher relationship' (Bergstrand and Savage 2013: 303).

We are aware of many cases in our programme (the MSc Clinical Education), and others, where face-to-face interactions are absent, yet there are still strong and trusting studentteacher relationships. We have developed practices over time that make use of our technologies and their accumulation of digital traces (email trails, online discussion postings, printed lists of student names, photos, occupations, locations, websites and search engines), to support social presence, communication and understanding of our students.

On the other hand, the assumption that face-to-face is inherently social and supportive is easily refuted by cases where on-campus students have not managed to build meaningful relationships with their teachers. We suspect that everyone reading this can imagine many such cases. Of course, even the claim that there are no face-to-face interactions in online learning is problematic, since communication through videoconferencing, Skype, FaceTime, etc., could be described as face-to-face, even if the faces are not present in a shared physical space (Fawns 2019). Where then does the material boundary lie between meaningful and meaningless interactions? We suggest that there is no boundary.

We would not argue that teaching online is the same as teaching face-to-face. Published literature (Kebritchi et al. 2017; Ryan et al. 2005), and our own interviews with staff new to teaching online (Aitken and Loads in press), shows that there is a significant adjustment and learning curve involved. However, the differences are often oversimplified. The primary challenge is in adapting principles and practices of teaching to encompass new and multiple contexts, rather than because online is a separate domain or because it is inherently more socially impoverished, isolating or flexible than face-to-face teaching. For us, the instrumental views highlighted above signal a need for the development of a wider repertoire of approaches and practices and a more critical conception of teaching. We see teaching, not in terms of crudely categorised approaches such as 'traditional', 'problem-based learning' or 'online learning' but as a potentially unbounded mix of diverse, subversive and unpredictable, digital and non-digital interactions. This is as true for a face-to-face, lecture-based, 'traditional' course as it is for a 'fully online' course (Fawns 2019).

Just as our online teaching is not temporally or spatially bounded, 'online learning' is not a separate domain, because learning does not really happen online. True, some of our students may sit alone at a desk with a computer in a room that is thousands of kilometres from the nearest physical campus of our institution, but their learning is still physical and embodied. Furthermore, our students do not do all of their learning at such desks. Learning carries on, away from the virtual learning environments of the programme (Fawns and O'Shea 2019). It filters into the physical settings of home, cafes, and workplaces and in transit between them. For example, it is not unusual for some of our students to engage with materials whilst on call in an emergency department or during family dinner time.

The material aspects of education are easily forgotten (Fenwick 2015; Hetherington and Wegerif 2018), even in face-to-face classrooms, and so it is not surprising that online learning is often discussed as if it is a disembodied experience that happens in a separate reality. Yet material objects and environments make significant contributions to online 
learning. There are, for example, many subtle acts of material configuration that play an important role in how students learn. In our video tutorials, we can see some of the ways in which students do this: the positioning a fan nearby to cool the air; the pre-tutorial ritual of making a cup of tea; the closing of doors to mute the sounds of children or pets; the moving from one device to another to work around technological constraints. Others can see and react to these material elements, even if the view of them is limited (e.g. by twodimensional video, photos or, in some cases, textual descriptions). These experiences make it clear that online learning happens in physical spaces (Bayne et al. 2014), and understanding the contribution of both social and material elements of online learning will help our students get the most out of their programme (e.g. by engaging in discussion with peers, or learning to configure their technologies).

The assumption that online learning can be unproblematically scaled up without significant additional cost or increased pressure on staff is implicit (or, sometimes, explicit) in a number of policies and initiatives in higher education (Selwyn 2007, 2010). In our experience, such instrumental conceptions of teaching do not fit many of the practices that happen in online learning. Whilst the same applies to face-to-face teaching, policies relating to workload, 'contact time' or appraisal, often based on a traditional, lecture-based timetable, can significantly misrepresent online teaching activity (Tynan et al. 2015). Whilst online courses are likely to feature a timetable, teaching is often not structured in such formal, scheduled terms, as either happening or not happening at a particular time. Online teaching is potentially always happening, in the sense that teachers can dip in and out of fora, respond to emails and post guidance or prompts that can be engaged with at any point in time.

The astute observer might argue that this has always been the case; teachers have always had to communicate with students about some aspect of their studying outside of scheduled teaching hours and formal communication channels. Perhaps this is just part of the job, for which teachers do not get much credit. Indeed, the thinking that we have to do as we develop online spaces prompts us to reconsider issues that have, in fact, always been there, surfacing largely hidden practices of teaching. Perhaps most importantly, this includes foregrounding the extent to which teaching involves activities of preparation and pre-configuration before scheduled activities (design) and of reaction, reconfiguration and subversion during them (orchestration) (Fawns 2019). However, pedagogical approaches that have developed alongside the evolution of technology in education shift the balance of the formal and informal (McWilliam 2008) such that elements that do not fit neatly into the official record may actually constitute the majority of an academic's teaching activity.

If the current success of our programme is to be maintained, our teaching must respond as much to the contexts of our students as to the online spaces in which our interactions take place. We must give them opportunities and appropriate support, to adapt their learning practices to suit the constraints of their settings (e.g. internet bandwidth, working environments, job demands and time zones). Elements of infrastructure can help or hinder, by changing teachers' and students' capacity to act effectively with the social and material resources available to them. As such, inflexible systems and tools, and standardised policies that do not account for the different needs of a diverse range of part-time, mature, professional or international students, compromise our ability to develop meaningful relationships and communities. 
In our view, successful online programmes are the result of students, teachers and administrators learning to work effectively within and around the constraints of infrastructure and policy. It follows that these collaborators should be supported to develop practices that work for them, both individually and collectively. The effective running of programmes requires a range of complementary expertise, and so the support and development of staff, along with the time requirement for that development, needs to be taken seriously. As such, evaluations of teaching, or of courses or programmes, should not only include but also foreground developmental aspects (Fawns et al. forthcoming). Further, evaluation should not only be focused on individuals and their particular performances but also on how different people, technologies, resources, environments and structures come together in social, material and digital activity. On our programme, we work hard to engage in regular, ongoing dialogue to reflect on emerging ideas, discuss approaches and practices, support each team member's development and develop a shared vision and values. All of this takes considerable time and expertise.

In online learning, just as in any other context, shared histories of practice foster emotive interdependence (Sutton 2018). Through a rich constellation of past encounters, a learning community is established in which embodied, emotive experiences take place and teachers transcend the mode of delivery, becoming 'authentic' (Kreber et al. 2007) through meaningful dialogue with students. This kind of online learning cannot be scaled up without significant additional cost because whilst technology can replicate resources and provide rich (or poor) possibilities for communication, it cannot solve the fundamental requirement of skilled staff spending time on, and with, each student.

Taking a view of all education as consisting of experiences in which material and digital activity combines in social and embodied encounters (Fawns 2019), we can guard against attempts to position online learning as a 'cash cow' (Feenberg 2019), where technology is seen as the solution to problems of scalability (Selwyn 2007) and where human meaning is incompatible with the logic of efficiency (Feenberg 1999). A critical postdigital perspective helps us to make judgements, not about 'online learning' in general but about the particular combinations and configurations of diverse elements that make up an online learning programme. By understanding how these configurations create rich or impoverished communication and relationships, we can see how increasing student numbers might change the parameters of design and influence our capacity to respond to the situated practices of students.

Acknowledgments Thanks to Michael Gallagher for his helpful insights and comments.

\section{References}

Aitken, G., \& Loads, D. (in press). Experiences of staff new to teaching postgraduate students online: implications for academic staff development. Journal of Perspectives in Applied Academic Practice.

Aitken, G., Jones, D., Fawns, T., Sutherland, D., \& Henderson, S. (2019). Using Bourdieu to explore graduate attributes in two online Master's programmes. Advances in Health Sciences Education. https://oi. org/10.1007/s10459-019-09885-6.

Bayne, S., Gallagher, M. S., \& Lamb, J. (2014). Being 'at'university: the social topologies of distance students. Higher Education, 67(5), 569-583. https://doi.org/10.1007/s10734-013-9662-4. 
Bergstrand, K., \& Savage, S. V. (2013). The chalkboard versus the avatar: comparing the effectiveness of online and in-class courses. Teaching Sociology, 41(3), 294-306. https://doi.org/10.1177/0092055X13479949.

Bjork. (2019). Technology with soul. http://www.bjork.fr/technology-with-soul,2605. Accessed 22 May 2019.

Fawns, T. (2019). Postdigital education in design and practice. Postdigital Science and Education, 1(1), 132145. https://doi.org/10.1007/s42438-018-0021-8.

Fawns, T., \& O’Shea, C. (2019). Evaluative judgement of working practices: reconfiguring assessment to support student adaptability and agency across complex settings. Italian Journal of Educational Technology, 27(1), 5-18. https://doi.org/10.17471/2499-4324/1027.

Fawns, T., Aitken, G., \& Jones, D. (forthcoming). Evaluation and the datafication of quality. Teaching in Higher Education.

Feenberg, A. (1999). Questioning technology. London: Routledge.

Feenberg, A. (2019). Postdigital or predigital? Postdigital Science and Education, 1(1), 8-9. https://doi. org/10.1007/s42438-018-0027-2.

Fenwick, T. (2015). Sociomateriality and learning: a critical approach. In D. Scott \& E. Hargreaves (Eds.), The sage handbook of learning (pp. 83-93). Los Angeles: SAGE.

Hetherington, L., \& Wegerif, R. (2018). Developing a material-dialogic approach to pedagogy to guide science teacher education. Journal of Education for Teaching, 44(1), 27-43. https://doi.org/10.1080 /02607476.2018.1422611.

Jones, C. (2019). Capital, neoliberalism and educational technology. Postdigital Science and Education. https://doi.org/10.1007/s42438-019-00042-1.

Kebritchi, M., Lipschuetz, A., \& Santiague, L. (2017). Issues and challenges for teaching successful online courses in higher education. Journal of Educational Technology Systems, 46(1), 4-29. https://doi. org/10.1177/0047239516661713.

Kreber, C., Klampfleitner, M., McCune, V., Bayne, S., \& Knottenbelt, M. (2007). What do you mean by "authentic"? A comparative review of the literature on conceptions of authenticity in teaching. Adult Education Quarterly, 58(1), 22-43. https://doi.org/10.1177/0741713607305939.

McWilliam, E. (2008). Unlearning how to teach. Innovations in Education and Teaching International, 45(3), 263-269. https://doi.org/10.1080/14703290802176147.

Ryan, M., Hodson-Carlton, K., \& Ali, N. S. (2005). A model for faculty teaching online: confirmation of a dimensional matrix. The Journal of Nursing Education, 44(8), 357-365.

Selwyn, N. (2007). The use of computer technology in university teaching and learning: a critical perspective. Journal of Computer Assisted Learning, 23(2), 83-94. https://doi.org/10.1111/j.1365-2729.2006.00204.x.

Selwyn, N. (2010). Looking beyond learning: notes towards the critical study of educational technology. Journal of Computer Assisted Learning, 26(1), 65-73. https://doi.org/10.1111/j.1365-2729.2009.00338.x.

Sutton, J. (2018). Shared remembering and distributed affect: varieties of psychological interdependence. In New directions in the philosophy of memory (pp. 181-199). https://doi.org/10.4324/9781315159591.

Tynan, B., Ryan, Y., \& Lamont-Mills, A. (2015). Examining workload models in online and blended teaching. British Journal of Educational Technology, 46(1), 5-15. https://doi.org/10.1111/bjet.12111. 